\title{
The EU regime for e-cigarettes: A rational compromise or regulatory failure?
}

\author{
Łukasz Gruszczyński \\ Institute of Law Studies of the Polish Academy of Sciences, Warsaw, Poland \\ Hungarian Academy of Sciences Centre for Social Sciences Institute for Legal Studies, Budapest, Hungary
}

\begin{abstract}
This article looks at the regulatory framework for e-cigarettes established by the European Union (EU) in its Tobacco Products Directive (TPD). In this context, it argues that overall the EU regime may be regarded as a realistic and reasonable compromise between proponents and opponents of the new technology. The TPD treats e-cigarettes as neither medicinal nor a tobacco product, but rather as a sui generis category that requires its own regulatory response. Although some of its solutions are clearly inspired by traditional tobacco control measures, they have also been modified in order to account for the harm reduction potential of e-cigarettes. At the same time, it also creates mechanisms, such as the notification and reporting requirements, that will facilitate its revision as our knowledge on e-cigarettes develops. Finally, the TPD leaves a certain regulatory space to the EU Member States, allowing them to reflect on particular national risk preferences and providing room for regulatory experimentation within the Union. Consequently, as an overall approach (but not necessarily with respect to its specific obligations), it may serve as a potential regulatory model for other countries, at least until more complete data on e-cigarettes become available.
\end{abstract}

KEY WORDS: e-cigarettes, TPD, EU, Tobacco Products Directive, regulation, harm reduction, precuationary principle.

ADDRESS FOR CORRESPONDENCE: Łukasz Gruszczyński, Institute of Law Studies of the Polish Academy of Sciences, 72 Nowy Świat Str., 00-330 Warsaw, Poland, e-mail: lukasz.gruszczynski@gmail.com

\section{INTRODUCTION}

Electronic cigarettes (e-cigarettes) are battery-powered devices designed to deliver nicotine by heating a solution that is inhaled by their users. Since their invention in 2003 [1], e-cigarettes have become increasingly popular among consumers around the globe. Many health specialists see them as part of a possible solution to the smoking epidemic [2]. Others, however, believe that they are simply another incarnation of traditional tobacco products and create an obstacle to the successful implementation of the endgame strategy (see, for example, [3]). This genuine lack of consensus among health experts, combined with the incompleteness of scientific data on the risks and benefits of e-cigarette use, has been translated into a heterogeneity of regulatory approaches taken by different countries. Some states classify e-cig- arettes as regular consumer products, others consider them as medicinal or tobacco products, or simply prohibit them from the market.

This article analyses the regulatory framework for e-cigarettes established by the European Union (EU) in its 2014 Tobacco Products Directive [4] (TPD). In this context, it argues that the EU regime, while not perfect, may be regarded as a rational (although not necessarily the best possible) compromise between proponents and opponents of the new technology. Its main features may be seen, at least until more complete data on e-cigarettes become available, as potential regulatory standards for other countries.

The article proceeds as follows: The next section briefly summarises the main elements of the TPD regime for e-cigarettes. The third section looks at the various 
concerns expressed by the critics of the directive and assesses their validity. The last part offers conclusions.

\section{THE EU REGULATORY REGIME FOR E-CIGARETTES}

Work on the new EU Tobacco Products Directive began in $2009^{1}$. The decision of the European Commission to update the existing tobacco control regime was motivated by various factors, including the development of new marketing strategies by the tobacco industry (e.g. innovative packaging and promotion methods at point of sale), changes in the market situation (e.g. expansion of novel smokeless tobacco products, introduction of conventional cigarettes with new features, or the emergence of e-cigarettes), scientific progress (e.g. new evidence concerning the impact of packaging on consumer behaviour), and legal developments at the international level, such as the adoption of the World Health Organisation's Framework Convention on Tobacco Control in $2003^{2}$. The whole process of preparing the directive lasted for more than five years and was characterised by intense lobbying by the tobacco industry as well as stark disagreement between Member States and EU institutions over the appropriate methods for achieving a balance between harmonisation of the internal market and public health protection (see, generally, [5]).

Prior to the adoption of the TPD, the EU Member States took diverse approaches to e-cigarettes. The majority of them considered them as medicinal products (e.g. Austria, Belgium, Denmark, Germany, and the Netherlands), some applied selectively specific restrictions taken from the traditional tobacco control repertoire, such as advertising controls or age limits (e.g. Malta or Poland), while others banned those products from their markets (e.g. Greece or Lithuania for imitation products). There was also a group of countries that left these products unregulated, subjecting them to general consumer protection rules (e.g. Bulgaria, Czech Republic, Ireland, and the United Kingdom) [6]. The initial draft directive presented by the Commission in December $2012^{3}$ classified e-cigarettes as medicinal products and referred them to the existing relevant EU regime. In practice such an approach would eliminate most of the products from the market. This was, however, later softened - partially due to pressure from public health circles (see, for example, [7]) - and a new sui generis regime for e-cigarettes was proposed.
The main objective of the TPD is to approximate the national laws of EU Member States concerning the manufacture, presentation, and sale of tobacco and related products, taking into account the need to guarantee a high level of health protection (see, for example, recital no. $5,6,8$, and 36 of the Directive). The rules on e-cigarettes constitute only a small section of the new law, as most of its space is dedicated to traditional tobacco products. The Directive defines e-cigarettes as products that 'can be used for consumption of nicotine-containing vapour via a mouth piece, or any component of that product, including a cartridge, a tank, and the device without cartridge or tank. Electronic cigarettes can be disposable or refillable by means of a refill container and a tank, or rechargeable with single-use cartridges' (Art. 2(17)). The Directive does not apply to those e-cigarettes that are classified as medicinal products (i.e. when they are marketed as smoking cessation devices $)^{4}$ and e-liquids or disposable devices that do not contain nicotine. The deadline for implementation of the Directive by Member States was set for 20 May 2016.

The TPD sets a maximum size of e-liquid containers $(10 \mathrm{ml})$, tanks, pods, and disposable e-cigarettes $(2 \mathrm{ml})$, as well as the level of nicotine in e-liquids $(20 \mathrm{mg} / \mathrm{ml})$. It provides that both containers and e-cigarettes need to be child - and tamper-proof and protected against breakage and leakage. Only high-purity ingredients can be used in the production of e-liquids (meaning that only trace levels of impurities, which are technically unavoidable during the manufacture process, can be present in a product), and, except for nicotine, no substance that poses a health risk may be added (unfortunately the TPD does not provide any additional guidance in this regard). E-cigarettes also need to deliver, under normal conditions of use, nicotine doses at consistent levels (Art. 20.3).

All e-cigarette products need to be properly labelled. This obligation includes a requirement of: (i) specific size health warnings on unit packets (30-35\% of the surface, depending on the number of official languages in a particular Member State); (ii) information concerning the ingredients, together with an indication of the nicotine content placed on outside packaging; and (iii) instructions for use and storage, risks for specific groups, and information on addictiveness and toxicity in the form of an attached leaflet (Art. 20.4). The TPD also prohibits certain elements from the packaging of e-cigarette products (e.g. suggestions that a product is less harmful than

${ }^{1}$ At that time, tobacco products were regulated by different EU acts, the most important being Directive 2001/37/EC of the European Parliament and of the Council of 5 June 2001 on the approximation of the laws, regulations and administrative provisions of the Member States concerning the manufacture, presentation and sale of tobacco products [2001] OJ L 194/26.

${ }^{2}$ See the Commission Staff Working Document, Impact Assessment, accompanying the document 'Proposal for a Directive of the European Parliament and of the Council on the approximation of the laws, regulations and administrative provisions of the Member States concerning the manufacture, presentation and sale of tobacco and related products, 19 December 2012, SWD(2012) 452 final.

${ }^{3}$ Proposal for a Directive of the European Parliament and of the Council on the approximation of the laws, regulations and administrative provisions of the Member States concerning the manufacture, presentation and sale of tobacco and related products, COM(2012)788 final.

${ }^{4}$ In such cases provisions of Directive 2001/83/EC of the European Parliament and of the Council of 6 November 2001 on the Community code relating to medicinal products for human use, OJ L 311/67 and Council Directive 93/42/EEC of 14 June 1993 concerning medical devices, OJ L 169/1 apply. 
others or that it has health or lifestyle benefits) (Art. 20.4 in connection with Art. 13). In this regard it follows the rules applicable to conventional tobacco products.

The TPD introduces a comprehensive ban on crossborder advertising, promotion, and sponsorship activities of e-cigarettes. This ban covers commercial communications on the internet, radio, and television (Art. 20.5). Member States may also (but are not required to) restrict internet sales of e-cigarettes (Art. 20.6 in connection with Art. 18).

The TPD establishes a notification and reporting system for manufacturers and importers of e-cigarettes and related products. The introduction of a new product (and this category includes all products that have been substantially modified) on the market is only possible after prior notification (but without a need for obtaining any kind of approval), with a six-month waiting period. The TPD lists information that has to be provided as a part of such a notification. In particular, this includes a product's ingredients and its emissions, toxicological data regarding both the product's ingredients and its emissions, information on the nicotine doses and uptake, and a description of the production process (Art. 20.2). Member States may ask for additional information if the data provided in a particular notification are incomplete. So far (as of July 2018), more than 185,000 such notifications - relating to both e-cigarettes and e-liquids - have been submitted [8].

Simultaneously, the TPD creates mechanisms for collecting market and scientific data on e-cigarettes and vaping. This is primarily an obligation on the part of manufactures and importers, who are required to submit, on an annual basis, information on sales volumes, preferences of various consumer groups, particularly young people and non-smokers (if such information is available to manufactures and importers, it needs to be stressed that those entities do not have any obligation to survey consumers about their product preferences), and modes of sale (Art. 20.7). They also need to establish their own systems for collecting data on suspected adverse effects from using e-cigarettes (Art. 20.9). Member States and the Commission are obliged to monitor the market and follow scientific developments in the field. On this basis the Commission will prepare an implementation report in 2021, which will address 'market developments and the role of these products for the initiation of consumption by young people and non-smokers and their impact on cessation efforts as well as measures taken by Member States regarding flavours' [8].

The TPD includes an emergency mechanism that allows Member States to take appropriate provision- al measures (including, inter alia, a marketing ban) if a particular product on the market is believed to present a serious risk to human health (Art. 22.11).

The TPD does not provide for the full harmonisation of the of e-cigarette market, and certain aspects are decided at the national level. In particular, Member States are free to regulate flavours in e-liquids, the application of smoke-free environment policies to e-cigarettes, domestic sales arrangements (e.g. sales via vending machines, internal long-distance sales), domestic advertising, and age limitations. In practice, most Member States (a notable exception is the United Kingdom, which permits certain forms of advertising) have decided to restrict domestic advertising and sponsorship activities, prohibit the use of e-cigarettes in public places, and introduce age limitations for the purchase of e-cigarettes. So far, no EU rules on the taxation of e-cigarettes have been adopted and Member States may apply a national tax to e-cigarettes, which they consider appropriate. Although the European Commission undertook some preliminary studies in this regard, it concluded that information on the e-cigarette market and their health effects was too limited to allow for any specific recommendation regarding tax treatment [9]. The Commission is planning to reassess this issue in 2019. In the meantime, some Member States have decided to introduce excise taxes on e-cigarettes (arguably motivated by fiscal rather than public health reasons) $)^{5}$, while others have taken a wait-and-see approach. However, the most important differences between Member States vis-à-vis the treatment of e-cigarettes concern restrictions on the use of flavours. Finland took the most restrictive approach and simply banned all flavoured e-liquids except for tobacco flavour. Hungary is planning to implement a similar restriction in 2020, while other Members may follow suit in the future - currently at least one of them (i.e. Estonia) is considering an analogous ban. In this context, they may be actually encouraged by the more aggressive approach to flavoured e-liquids taken recently by the US Food \& Drug Administration (i.e. a planned ban on the sale of most flavoured e-cigarettes in convenience stores and gas stations $)^{6}[10]$.

\section{ASSESSING THE EU REGULATORY REGIME}

The regulatory model introduced by the TPD has been heavily criticised. Interestingly, the Directive has been opposed not only by the e-cigarette industry, individual vapers, and their associations, but also by a number of public health experts (see, for example $[7,11]$ ). Several different concerns have been raised. For example, it has been argued that the TPD relies too heavily on tra-

\footnotetext{
This group includes, in particular, Italy, Portugal, Romania, Slovenia, Latvia, Hungary, Finland, Greece and Croatia. There are other countries that are planning to introduce such taxes in the near future. For example, Poland will begin to do so starting from 30 June 2020.

${ }^{6}$ Note that the FDA action is focused on sales of flavoured products to youth. Consequently, menthol flavoured products would still be available in convenience stores and gas stations while other flavors in specific age-verified settings.
} 
ditional tobacco control policies when setting standards for e-cigarettes. Others have claimed that by limiting the variety of the available products the regulators will push consumers to the black market, or back to smoking combustible tobacco (see, for example, [12]). It has also been argued that compliance with additional (and 'unnecessary') requirements will increase the costs of e-cigarette products, thus making them less attractive to consumers in comparison to ordinary tobacco products [13].

A more elaborate criticism was presented by Clive Bates - a well-known pro-e-cigarette activist - who described the relevant provisions of the Directive as 'a catalogue of poorly designed, disproportionate, and discriminatory measures that will achieve nothing useful but do a great deal of harm' [14]. In particular, he criticised: (i) the complete ban on advertising and promotion of e-cigarettes, which in his opinion shields tobacco products from a new disruptive technology; (ii) the limitation on the strength of e-liquids and the size of their containers, as this restricts the innovation and makes the final product less attractive for heavily dependent smokers and those in the process of switching; (iii) health warnings, which he considers excessive, considering the lower risk profile of e-cigarettes as compared to tobacco products; (iv) the notification obligation (again as being too excessive with respect to the data that need to be provided); (v) protection against leakages, as this may lead to the elimination of certain product categories - particularly mods and tanks - from the market, thus decreasing the overall attractiveness of e-cigarettes as an alternative to tobacco products; (vi) opening the door to classifying e-cigarettes as medicinal products by Member States, which in practice would eliminate most of the products from the market; and (vii) the introduction of an emergency mechanism, which may be abused by Member States [14].

Some of the above concerns were included in a 2015 report issued by the Public Health England (PHE). The report in particular observed that " $\mathrm{t}]$ he TPD certainly raises the barrier for bringing [e-cigarette] products to market or continuing to market existing products and will undoubtedly constrain the [e-cigarette] market.' The report also noted that 'the cap on nicotine concentrations introduced by the TPD will take high nicotine [e-cigarettes] and refill liquids off the market, potentially affecting heavier smokers seeking higher nicotine delivery products' [15]. The more recent report of the Science and Technology Committee of the House of Commons has also identified similar 'deficiencies' in the TPD regime:

Some aspects of the regulatory system for e-cigarettes appear to be holding back their use as a stop-smoking measure. The limit on the strength of refills makes means that some users have to puff harder to get the nicotine they seek and may put some heavy smokers off persisting with them. The restriction on tank size does not appear to be founded on scientific evidence, and should therefore urgently be reviewed. A prohibition on making claims for the relative health benefits of switching to e-cigarettes means that some who might switch are not getting that message [16].

It is true that the TPD is not an instrument that would endorse the harm reduction philosophy for e-cigarettes. At the same time, it seems that proper assessment and appreciation of the TPD regime cannot be made in isolation from the practice of other states. Many jurisdictions, including a number of developed countries, simply prohibit the marketing of e-cigarettes (e.g. Australia, Brazil, Singapore, and Taiwan). Others impose overly high thresholds (in financial, technical, and logistic terms) for entering the market by classifying e-cigarettes as medicinal products (e.g. Jamaica, Chile, Japan, or South Africa). Finally, there is a group of countries that subject e-cigarettes to the rules that are applicable to traditional tobacco products (e.g. Georgia, Paraguay, or Vietnam) ${ }^{7}$. Seen from this perspective, the EU regulatory regime appears to be quite liberal and receptive - at least to some extent - to the harm reduction arguments, as evidenced by, for example, the mere fact of allowing e-cigarettes on the EU market. From the harm reduction point of view, the TPD also constitutes a step forward as compared to the regulatory situation in most of the Member States prior to its adoption that was dominated by restrictions on marketing of e-cigarettes either by banning them or treating them as medicinal products. Of course, there are also some states (e.g. Ukraine, China, and Russia) that leave e-cigarettes unregulated, but such an approach can hardly be deemed advisable considering that there is a scientific consensus that e-cigarettes pose some - even if relatively small when compared to tobacco products - health-related risks. In any case, lack of regulation is rarely a sign of application of a harm reduction policy but rather is an expression of the low priority of, or lack of consensus over, the specific issue on the regulatory agenda.

While some of the concerns expressed by critics of the TPD appear to be well-founded (e.g. the cap on the strength of e-liquid and size of e-liquid containers, in light of other less restrictive measures that could address the risk of poisoning), it seems that many other concerns are either misplaced, overstated, or unsupported by the relevant empirical data. Although it is true that a number of specific regulatory solutions envisaged by the TPD have been modelled on traditional tobacco control measures, it should also be recognised that they have been adjusted to account for the reduced risk profile of e-cigarettes and their harm reduction potential. 
For example, while the TPD requires health warnings on e-cigarettes and related products, this obligation is less demanding than for tobacco products. The directive only demands textual rather than combined (i.e. text and picture) health warnings and has smaller size requirements (30\% of a front of package vs. $65 \%$ on both sides of the package for tobacco products). Moreover, warnings are formulated in a more neutral way, without an appeal to users' emotions ('This product contains nicotine, which is a highly addictive substance'). For traditional tobacco products the catalogue is replete with messages that are designed to provoke emotional reactions on the part of an addressee ('Smoking can kill your unborn child') ${ }^{8}$. The same is true for the ban on characteristic flavours of tobacco products (Art. 7), while in the case of e-cigarettes the issue remains unregulated at the EU level. Another difference relates to the overall standardisation of packaging, which is extensive in the case of traditional tobacco products and limited in the case of e-cigarettes 9 .

So far there are no indications that the entry into force of regulations implementing the TPD has pushed the consumers to the black market - actually it seems that consumers across the EU have adjusted to the new regulatory environment. There are no empirical data that support the claim of a higher number of vapers returning to smoking due to unavailability of high nicotine concentration e-liquids. In fact, as the 2017 report by the Action on Smoking and Health (ASH) shows, only a small fraction of British vapers use high-nicotine-concentration e-liquids $(19 \mathrm{mg} / \mathrm{ml})$ or consume more than $4 \mathrm{ml}$ of e-liquid per day ( $9 \%$ and $11 \%$, respectively) [17] Consequently, as summarised by Deborah Arnott, the Chief Executive of the ASH, '[t]he new ASH research shows that most vapers use less nicotine than the limit set in the new EU regulations and are likely to have to refill their devices no more than a couple of times a day. Concerns that the EU regulations would force the products most vapers use off the market seem to have been overstated' [18]. The same is true for the notification and reporting obligations. Already in 2016, the Royal College of Physicians stated that although 'it is inevitable that these reporting and performance requirements will impose costs on manufacturers and importers, these TPD measures appear to be congruent with the basic regulatory objective of ensuring that products are fit for purpose, and reasonably safe' [19]. This was confirmed by the most recent report commissioned by the PHE, which noted that a high number of notifications (about 32,000 ) suggests 'a level of compliance with the regula- tions, and that the notification process is not too onerous' [20]. At the same time, it allows for the collection of data that will be used to reassess the effectiveness of the TPD regime.

Finally, some of the concerns seem to relate to requirements that may be (and in fact were) introduced at the national level rather than being required by the TPD. It should be borne in mind that restrictions on marketing at point of sale, billboards, bus stops, and other advertising that does not cross borders, use of flavours in e-liquids, and taxation of e-cigarettes, are decided by individual Member States within their own prerogatives. This provides ample room for the implementation of either more or less harm reduction-centred strategies.

\section{CONCLUSIONS}

The TPD, with its sui generis legal regime for e-cigarettes, should be seen as a rational (albeit not perfect) and realistic compromise between the proponents and opponents of the new technology. It recognises the harm reduction potential of the products but also acknowledges the existing uncertainties resulting from gaps in knowledge and contradictory scientific views (e.g. on the long-term consequences of e-cigarette use, or the gateway potential of the products) as well as the systemic problems that the technology may create (i.e. the renormalisation effect) [14, 21]. At the same time, it also creates mechanisms, such as the notification and reporting requirements, that will facilitate its revision as our knowledge on e-cigarettes develops. Finally, the TPD leaves a certain regulatory space to the EU Member States, allowing them to reflect on particular national risk preferences and providing room for regulatory experimentation. Consequently, as an overall approach (but not necessary with respect to its specific obligations), it may serve as a potential regulatory model for other countries, at least until more complete data on e-cigarettes become available.

\section{ACKNOWLEDGEMENTS}

This research was financed by the National Science Centre (Poland) pursuant to grant number UMO-2016/ 21/B/HS5/02065

\section{DISCLOSURE}

The author reports no conflict of interest.

\section{References}

1. Sleight VJ. A brief history of the electronic cigarette. J Lung Pulm Respir Res 2016; 3: 00097.

${ }^{8}$ But see Cox S, Frings D, Ahmed R, Dawkins L. Messages matter: The Tobacco Products Directive nicotine addiction health warning versus an alternative relative risk message on smokers' willingness to use and purchase an electronic cigarette. Addict Behav Rep. 2018; 8:136-139 (arguing that '[p]reliminary findings suggest that the TPD e-cigarette health warning may reduce smokers' willingness to use and likelihood of purchasing an e-cigarette. Messages conveying reduced harm, or indeed no message at all, may be more effective in encouraging smokers to switch to these lower risk products').

${ }^{9}$ This was also the perception of the Advocate General in the case C-477/14 Pillbox 38 (UK) Limited v The Secretary of State for Health who highlighted more favourable treatment of e-cigarettes as compared to traditional tobacco products (Opinion of Advocate General Kokott delivered on 23 December 2015 in case C-477/14 Pillbox 38 (UK) Limited v The Secretary of State for Health [2015] ECLI:EU:C:2015:854, para. 41). 
2. Statement from specialists in nicotine science and public health policy sent to Dr Magaret Chan, Director General of the World Health Organization, 26 May 2014. Available from: https:// nicotinepolicy.net/documents/letters/MargaretChan.pdf (accessed: 15 November 2018).

3. Open letter to Dr. Margaret Chan, Director General of the World Health Organization, 16 June 2014. Available from: https://bit. ly/2PYDVEa (accessed: 15 November 2018).

4. Directive 2014/40 (EU) of the European Parliament and of the Council on the approximation of the laws, regulations and administrative provisions of the Member States concerning the manufacture, presentation and sale of tobacco and related products [2014] OJ L 127/1. Available from: https://eur-lex. europa.eu/eli/dir/2014/40/oj (accessed: 15 November 2018).

5. Peeters S, Costa H, Stuckler D, et al. The revision of the 2014 European tobacco products directive: an analysis of the tobacco industry's attempts to 'break the health silo'. Tob Control 2016; 25: 108-117.

6. Commission Staff Working Document, Impact Assessment (n. 6), p. 26. Available from: http://ec.europa.eu/competition/antitrust/ actionsdamages/impact_assessment_en.pdf(accessed: 15 November 2018).

7. The letter 'E-cigarettes are helping smokers', Financial Times, 2 December 2013. Available from: http://www.ft.com/cms/ s/0/e8f599e8-584d-11e3-9da6-00144feabdc0.html (accessed: 15 November 2018).

8. Answer given by Mr. Andriukaitis on behalf of the European Commission, 8 August 2018, Question reference: E-003629/2018. Available from: https://bit.ly/2DeljXA (accessed: 15 November 2018).

9. European Commission Report from the Commission to the Council on Directive 2011/64/EU on the structure and rates of excise duty applied to manufactured tobacco, Brussels, 12.1.2018 $\operatorname{COM(2018)~} 17$ final. Available from: https:// ec.europa.eu/taxation_customs/sites/taxation/files/report excise_duty_manufactured_tobacco_12012018_en.pdf (accessed: 15 November 2018).

10. McGinley L. FDA plans curbs on e-cigarette sales over concerns about surge in teen vaping, The Washington Post, 8 November 2018. Available from: https://wapo.st/2Dfxl58 (accessed: 15 November 2018).

11. Scientific Errors in the Tobacco Products Directive. A letter sent by scientists to the European Union, 17 January 2014. Available from: https://bit.ly/2Tn30HQ (accessed: 15 November 2018).
12. Doward J. New laws in UK 'stifling vaping's success' in curbing smoking, The Guardian, 20 May 2017. Available from: https:// bit.ly/2qFfCOj (accessed: 15 November 2018).

13. Snowdon Ch. E-cigarettes and Article 20 of the Tobacco Products Directive, undated, Epicenter. Available from: https://bit. ly/1iuZ6tk (accessed: 15 November 2018).

14. Bates C. What is wrong with the Tobacco Products Directive for vapour products?, The Counterfactual, 22 May 2015. Available from: https://www.clivebates.com/what-is-wrong-withthe-tobacco-products-directive-for-vapour-products/ (accessed: 15 November 2018).

15. McNeill A, Brose LS, Calder R, et al. E-cigarettes: an evidence update. A report commissioned by Public Health England, London 2015, p. 23. Available from: https://www.gov.uk/government/publications/e-cigarettes-an-evidence-update (accessed: 15 November 2018).

16. House of Commons, Science and Technology Committee, E-cigarettes - Seventh Report of Session 2017-19, HC 505, 17 August 2018, at 4. But see Knapton S., MPs behind controversial e-cigarette report criticized for vaping lobby links. The Telegraph, 17 August 2018. Available from: https://bit. ly/2BTNMVJ (accessed: 15 November 2018).

17. ASH. Use of e-cigarettes (vapourisers) among adults in Great Britain, May 2017. Available from: https://bit.ly/2RRhuhc (accessed: 15 November 2018).

18. ASH. New EU rules on nicotine strength not a problem for most vapers, 16 May 2016. Available from: https://bit.ly/2z87Yjc (accessed: 15 November 2018).

19. Royal College of Physicians. Nicotine without smoke. Tobacco harm reduction. A report of the Tobacco Advisory Group of the Royal College of Physicians, April 2016, p. 159. Available from: https://www.rcplondon.ac.uk/file/3563/download?token=Mu0K_ ZR0 (accessed: 15 November 2018).

20. McNeill A, Brose LS, Calder R, et al. Evidence review of e-cigarettes and heated tobacco products 2018. A report commissioned by Public Health England, London 2018, p. 10. Available from: https://assets.publishing.service.gov.uk/government/ uploads/system/uploads/attachment_data/file/684963/Evidence_review_of_e-cigarettes_and_heated_tobacco_products_2018.pdf (accessed: 15 November 2018).

21. European Public Health Association, Facts and fiction on e-cigs, undated. Available from: https://eupha.org/repository/ advocacy/EUPHA_facts_and_fiction_on_e-cigs.pdf (accessed: 15 November 2018).

Łukasz Gruszczyński is an Associate Professor of International Law at the Institute of Law Studies of the Polish Academy of Sciences and an External Research Fellow at the Hungarian Academy of Sciences CSS Institute for Legal Studies. He is the author of more than 50 publications and editor of the forthcoming book 'The Regulation of E-cigarettes: International, European and National Challenges', which will be published by Edward Elgar Publishing in 2019. His current research focuses on international trade law, international investment law, and risk regulation. 